\title{
Um estudo sobre a utilização de Símbolos Pictóricos Táteis em Mapas Temáticos para o Ensino de Geografia no âmbito do Desenho Universal
}

\author{
Andrea Faria Andrade* \\ Caroline de Castro Monteiro*
}

Recebido 19 de abril de 2019; aceito 21 de junho de 2019

\begin{abstract}
This work aimed to evaluate the use of tactile thematic maps with pictorial symbology, to be used based on the Universal Design for Learning (DUA). Thus, it is possible to use the teaching material by all children, promoting the inclusion of visually impaired students to social experience and communication with visionaries. For that, two maps were made with patterns of distinct symbologies: pictorial and abstract. The maps were modeled in 3D software and printed using Rapid Prototyping technology. Perception tests of these symbologies were performed with visually impaired and visually impaired students in a school in Curitiba, Paraná. From the first results obtained in this research, it is suggested that pictorial symbology be indicated to be used for the representation of punctual features in tactile mapping, as it was more attractive to all participants and stimulated students with visual impairment to social interaction and to use beyond touch, language, which contains the principles of Universal Design. However, as with the use of pictorial symbols for seers, some symbols are apprehended as they are observed and used in everyday life, making them subject to standardization and being used universally. The design of these symbols from 3D printing proved effective because it allows the modeling of complex geometries, which allows the combination of visual and tactile resources to generate maps from the perspective of Universal Design, as well as producing durable and easily reproduced materials.
\end{abstract}

Key words: Touch maps, universal design, geography education, touch symbols, rapid prototyping.

* Universidade Federal do Paraná, Brasil, e-mails: afariandrade@gmail.com, carolc.monteiro1@gmail.com. 


\section{Resumo}

Esse trabalho pretendeu avaliar o uso de mapas temáticos táteis com simbologia pictórica, a serem utilizados com base no Desenho Universal para a Aprendizagem (DUA). Desta forma, é possível a utilização do material didático por todas as crianças, promovendo a inclusão dos estudantes com deficiência visual à experiência social e à comunicação com os videntes. Para tanto, foram confeccionados dois mapas com padrões de simbologias distintas: pictórica e abstrata. Os mapas foram modelados em software 3D e impressos através da tecnologia de Prototipagem Rápida. Foram realizados testes de percepção destas simbologias com estudantes videntes e com deficiência visual em um colégio de Curitiba, Paraná. A partir dos primeiros resultados obtidos nessa pesquisa, sugere-se que a simbologia pictórica seja indicada a ser utilizada para a representação de feições pontuais no mapeamento tátil, pois a mesma se mostrou mais atrativa a todos os participantes e estimulou os alunos com deficiência visual à interação social e a utilizar além do tato, a linguagem, o que contenta os princípios do Desenho Universal. Entretanto, assim como ocorre com a utilização de símbolos pictóricos para pessoas videntes, alguns símbolos são apreendidos na medida em que os mesmos são observados e utilizados no dia a dia, o que os tornam passíveis a uma padronização, sendo empregados de forma universal. A concepção destes símbolos a partir da impressão 3D se mostrou eficaz pois permite a modelagem de geometrias complexas, o que permite combinar recursos visuais e táteis para gerar mapas dentro da perspectiva do Desenho Universal, além de produzir materiais duráveis e de fácil reprodução.

Palavras chave: Mapas táteis, desenho universal, ensino de Geografia, símbolos táteis, prototipagem rápida.

\section{Resumen}

Este trabajo tuvo como objetivo evaluar el uso de mapas temáticos táctiles con simbología pictórica, que se utilizarán en base al Diseño Universal para el Aprendizaje (DUA). Por lo tanto, es posible utilizar el material didáctico de todos los niños, promoviendo la inclusión de estudiantes con discapacidad visual en la experiencia social y la comunicación con visionarios. Para eso, se hicieron dos mapas con patrones de simbologías distintas: pictórica y abstracta. Los mapas se modelaron en software 3D y se imprimieron utilizando la tecnología Rapid Prototyping. Las pruebas de percepción de estas simbologías se realizaron con estudiantes con discapacidad visual y visual en una escuela en Curitiba, Paraná. A partir de los primeros resultados obtenidos en esta investigación, se sugiere que se indique que la simbología pictórica se utiliza para la representación de características puntuales en el mapeo táctil, ya que era más atractiva para todos los participantes y estimulaba a los estudiantes con discapacidad visual a interacción social y para usar más allá del tacto, lenguaje, que contiene los principios del diseño universal. Sin embargo, al igual 
que con el uso de símbolos pictóricos para los videntes, algunos símbolos son aprehendidos a medida que se observan y usan en la vida cotidiana, haciéndolos sujetos a la estandarización y al uso universal. El diseño de estos símbolos de la impresión 3D demostró ser efectivo porque permite el modelado de geometrías complejas, lo que permite la combinación de recursos visuales y táctiles para generar mapas desde la perspectiva del Diseño Universal, así como para producir materiales duraderos y fácilmente reproducibles.

Palabras clave: Mapas táctiles, diseño universal, educación en geografía, símbolos táctiles, creación rápida de prototipos.

\section{Introdução}

O desenvolvimento do projeto cartográfico é parte integrante do processo de comunicação cartográfica. A relação entre o projeto cartográfico e a comunicação cartográfica (conjunto dos símbolos, cores, etc.) não ocorre apenas pela definição da linguagem cartográfica de cada mapa, mas também pelo uso dos mesmos. Desta forma, a tarefa inicial no desenvolvimento de um projeto cartográfico é entender e estabelecer os usos que serão destinados aos mapas que serão construídos (Sluter, 2008).

A comunicação cartográfica, portanto, alcança os resultados esperados quando o uso dos mapas ocorre com base em conhecimentos que são comuns ao produtor do mapa e ao usuário, caracterizados no modelo de comunicação cartográfica de Koláčný como as "realidades do produtor do mapa e do usuário" (Figura 1). Desta forma, no projeto de mapas táteis para o uso no Ensino, o ponto de vista dos professores especialistas em educação inclusiva é fundamental para a elaboração do mapa junto ao produtor do mesmo, pois juntos conseguirão chegar a um resultado satisfatório, utilizando os conhecimentos de ambos para chegar a uma solução eficaz.

Para López (2012) o conceito de inclusão sugere o desenvolvimento de processos e práticas que procuram proporcionar a alunos com deficiências uma educação tão comum quanto possível, evitando a sua segregação. Compreende-se, deste modo, que a preocupação atual se concentre na aplicação prática de uma pedagogia inclusiva, procurando-se identificar os modelos pedagógicos que facilitem a inclusão social e acadêmica, assegurando assim o envolvimento e a participação de todos os alunos (Katz, 2013 cit. por Nunes e Madureira, 2015).

Nesse sentido, portanto, o Desenho Universal para a Aprendizagem pode reduzir as barreiras ao ensino e à aprendizagem. O conceito de Desenho Universal para a Aprendizagem (DUA), de acordo com Oka et al. (2017) têm sido caracterizado como base às necessidades de todos os alunos, incluindo alunos com deficiências $\mathrm{e}$ estudantes com diferenças culturais e linguísticas. A definição se aprimorou a partir 


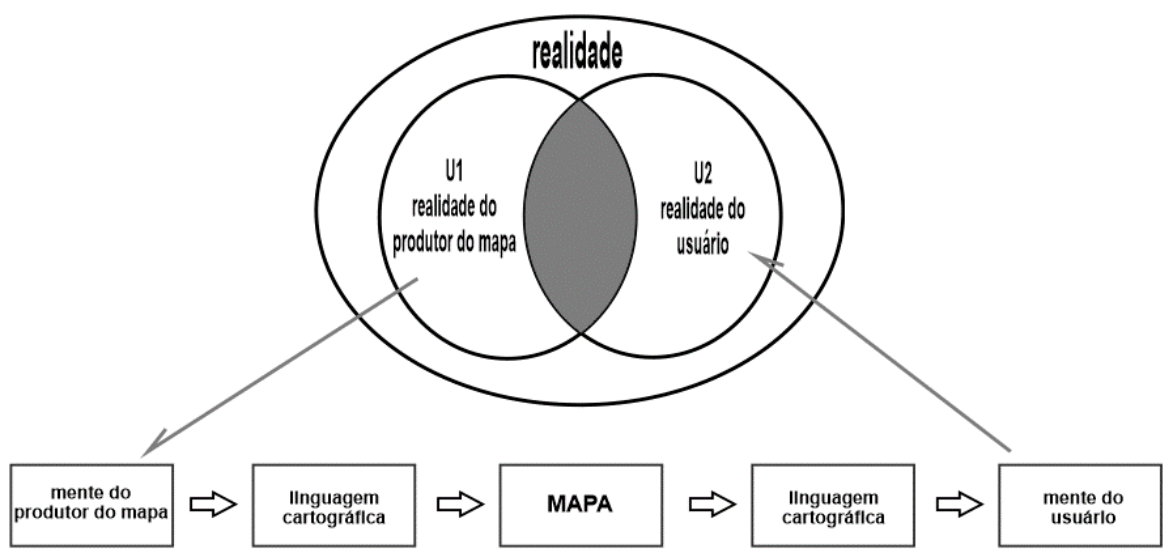

Figura 1. Versão simplificada do modulo de comunicação cartográfica de Kolacny (1977). Fonte: adaptado de Sluter (2008).

de discussões de profissionais da área de arquitetura da Universidade da Carolina do Norte, nos EUA, cujo objetivo principal foi definir um projeto de produtos e ambientes para ser usado por todos, sem a necessidade de adaptação ou projeto especializado para pessoas com deficiência (Carletto e Cambiaghi, 2018).

O projeto desenvolvido segundo a abordagem do Desenho Universal, conforme comentam Carletto e Cambiaghi (2018), é o processo de criar produtos acessíveis a todas as pessoas, independentemente de suas características pessoais, idade, ou habilidades, e conforme comentam Oka et al. (2017), tem havido grande interesse em integrar a estrutura do DUA em ambientes educacionais.

Quanto a sua aplicação, embora os componentes que compõem a estrutura do DUA sejam baseados em práticas apoiadas por pesquisas, ainda há uma lacuna sobre como o DUA pode ser efetivamente aplicado ao currículo e à utilização para dar suporte à diversidade de alunos (Oka et al., 2017).

Dessa forma, pretendeu-se com essa pesquisa verificar a possibilidade da utilização de símbolos pictóricos táteis nas representações de mapas temáticos para que os mesmos possam ser percebidos e compreendidos, tanto por crianças com deficiência visual quanto por videntes, nos usos destes mapas. Parte-se da premissa de que uma diferença visual não representa em si mesma, alterações nas possibilidades de aprendizagem da criança, na sua capacidade de estabelecer relações com os outros, com objetos e situações que acontecem ao seu redor, pois conforme comenta Lira e Schlindwein (2008), como qualquer outra, a criança com deficiência visual precisa de oportunidades, de convivência com seus pares, de forma que possa aprender a se relacionar com o mundo. De acordo com os autores, "a criança cega 
pode perfeitamente se apropriar das significações de seu meio e participar das práticas sociais, pois dispõe do instrumento necessário para isso - a linguagem".

O presente trabalho pretendeu avaliar a possibilidade de uso de mapas temáticos com simbologia pictórica tátil para serem utilizados com base no DUA, ou seja, na produção de um material didático com a possibilidade de utilização por todas as crianças, promovendo desta forma a inclusão dos estudantes com deficiência visual, e, portanto, a experiência social e a comunicação com os videntes, possibilitando ainda mais a inclusão no ambiente escolar.

O tipo de pesquisa empregado foi a pesquisa qualitativa exploratória, ou seja, que se dedica a determinado tema pouco explorado e de difícil elaboração de hipóteses precisas, contribuindo muitas vezes para uma investigação mais ampla (Gil, 2017). Para tanto, foram testados dois mapas, um com a simbologia abstrata e outro com a simbologia pictórica, a fim de explorar a possibilidade da utilização destes símbolos para os deficientes visuais. Além disso, pretendeu-se explorar a possibilidade de uso da Prototipagem Rápida na elaboração destes mapas.

\section{O Desenho Universal para a Aprendizagem (DUA)}

De acordo com Araújo (2018), “o empoderamento das pessoas com deficiência pela inclusão e igualdade de direitos passou a conquistar notoriedade e novas formas de ensino, oportunidades e tecnologias inclusivas vem sendo desenvolvidas". A escola pode ser, portanto, um espaço privilegiado de aprendizagem também para a criança cega ou com baixa visão. "Importa que a educação seja orientada em direção à plena validez social e a considere como um ponto real e determinante, e não que se nutra da ideia de que o cego está condenado a menos valia" (Vigotski, 1989: 54).

Neste contexto, o Desenho Universal ingressa no sentido de proporcionar a integração e à socialização das crianças com deficiência visual no ambiente escolar. Vygotski (1997) destaca a possibilidade das pessoas com deficiência visual de utilizar a percepção visual de outra pessoa, a experiência alheia como instrumento para ver. A fonte da compensação para a pessoa com deficiência visual não seria, portanto, "o desenvolvimento do tato ou a maior sutileza do ouvido, mas a linguagem, quer dizer, a utilização da experiência social, a comunicação com os videntes" (Vygotski, 1997: 107).

Conforme comentam Carletto e Cambiaghi (2018), a ideia do Desenho Universal é, justamente, evitar a necessidade de ambientes e produtos especiais para pessoas com deficiências, assegurando que todos possam utilizar com segurança e autonomia os diversos espaços construídos e objetos. O conceito de Desenho Universal para a Aprendizagem (DUA) é geralmente atribuído a David Rose, Anne Mayer e seus colegas do Center for Applied Special Technology (CAST) (Edyburn, 2010; Alves, Ribeiro e Simões, 2013 cit. por Nunes e Madureira, 2015) e referem-se a princípios e estratégias relacionadas à melhoria do processo de ensino-aprendizagem. O DUA 
baseia-se no conhecimento resultante de pesquisas e práticas oriundas de várias áreas do saber: a educação, a psicologia do desenvolvimento, as ciências cognitivas, e ainda nos princípios do Desenho Universal (Nunes e Madureira, 2015).

Com base na ideia de que cada aprendiz é diferente e tendo como finalidade facilitar o acesso de todos os alunos ao currículo comum, CAST desenvolveram três princípios (Figura 2). De acordo com Nunes e Madureira (2015), o primeiro princípio preconiza que a motivação desempenha um papel crucial na aprendizagem, e, desta forma, reconhece que os alunos diferem nos seus interesses e nas formas como podem ser envolvidos e motivados para aprender. De acordo com a CAST (2011) "alguns alunos envolvem-se de forma espontânea e preferem as novidades, enquanto outros elegem a rotina; alguns podem gostar de trabalhar sozinhos, enquanto outros preferem trabalhar com os seus pares". Entretanto, não há um meio de envolvimento e de motivação ideal para todos os alunos em todos os contextos, e, portanto, é essencial proporcionar múltiplas opções para envolver e motivar os alunos para a aprendizagem.

No segundo princípio considera-se que "os alunos diferem no modo como percebem e compreendem a informação que lhes é apresentada" (CAST, 2011: 5), e desta forma, conforme afirmam Dean et al. (2017) e Nunes e Madureira (2015), recorrer a diferentes formas de abordar o conteúdo e transmitir a informação. $\mathrm{O}$ terceiro princípio pressupõe que "os alunos diferem no modo como podem participar nas situações de aprendizagem e expressar o que sabem" (CAST, 2011: 5), e.g. alguns podem ser capazes de se expressar bem através da fala, mas não através da escrita, ou vice-versa.

Neste sentido, os mapas táteis com a simbologia pictórica podem contribuir como uma ferramenta do DUA instigando à motivação aos estudantes videntes, já que seriam representados com figuras pictóricas com uma relação semântica ao objeto real. Ademais, podem ser um instrumento motivador aos alunos com deficiência visual, conduzindo à experiência social e a comunicação com os colegas videntes, como abordado por Vygotski (1997). Os mapas podem propiciar alternativa de representação e apresentação do conteúdo para todos os estudantes, estimulando os alunos com deficiência visual à interação social e a utilizar além do tato, a linguagem, o que contenta os princípios do Desenho Universal.

\section{Cartografia Tátil e a Tecnologia de Impressão 3D}

Nogueira (2010) comenta que a história dos mapas táteis se inicia quando perceberam a carência que existia para atender necessidades educacionais. A primeira experiência dos materiais táteis foi desenvolvida por Samuel Gridley em1837, mas apenas na década de 70, as pesquisas sobre o ensino de pessoas com necessidades especiais foram inseridas na produção dos mapas, assim criando um pensamento com a finalidade de orientação e mobilidade. 


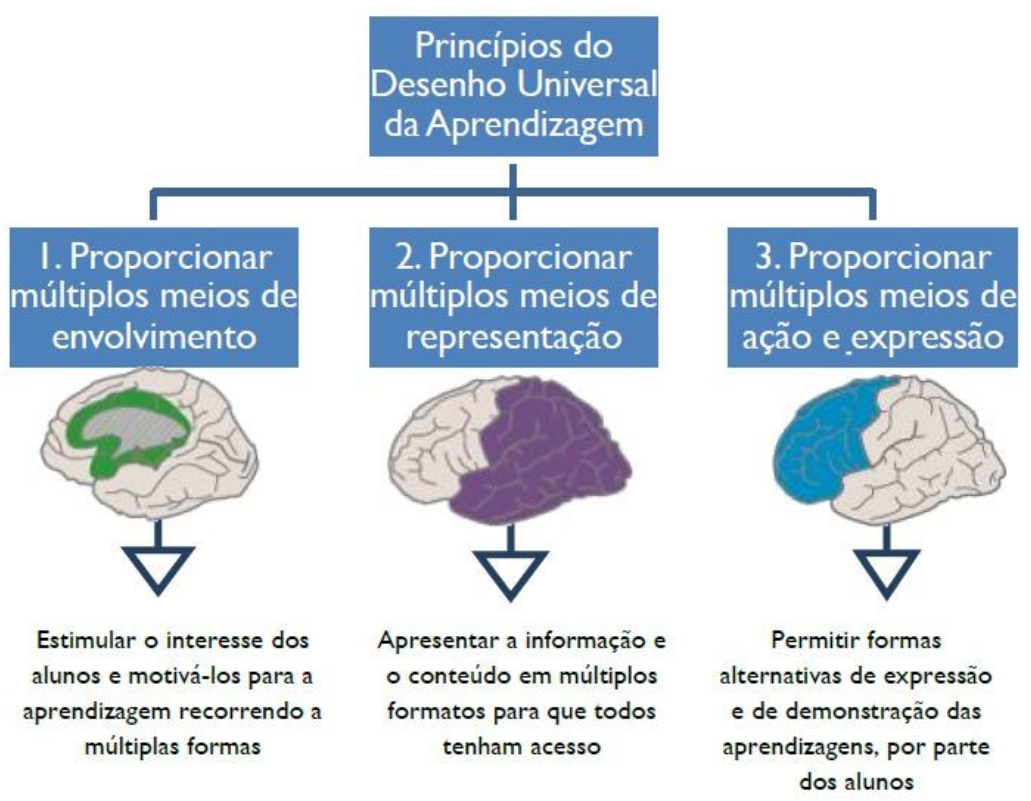

Figura 2. Princípios básicos do Desenho Universal para a Aprendizagem DUA. Fonte: Nunes e Madureira (2015).

De acordo com Loch (2008) cit. por Araújo (2018), a Cartografia Tátil confere "um ramo específico da Cartografia que se ocupa da confecção de mapas e outros produtos cartográficos que possam ser lidos por pessoas cegas ou com baixa visão". As representações cartográficas táteis são desenvolvidas em cada país de acordo com técnicas e equipamentos disponíveis. Ainda não existem padrões cartográficos táteis aceitos mundialmente, como acontece na cartografia tradicional, e, portanto, cada país desenvolve seus padrões e estabelece normas para a cartografia tátil, tomando como base a matéria-prima e desenvolvimento tecnológico existente, a acessibilidade e o preparo dos deficientes visuais para uso desses produtos.

Para Loch e Almeida (2006), os mapas devem ser apresentados aos usuários com deficiência visual como um conjunto harmonioso de símbolos e texturas e utilizando uma forma simplificada de representar essa informação. Estas questões de representação aliadas aos sistemas de produção destes mapas se tornam mais relevantes devido as melhorias das técnicas de produção, como a tendência emergente da Prototipagem Rápida, sobre os sistemas tradicionais como as técnicas de Microcapsulação e a Termoformagem (Dean et al., 2017).

O princípio da tecnologia de Microcapsulação, de acordo com Araújo (2018), utiliza um tipo especial de papel com microcápsulas de álcool incorporadas que se dilatam quando exposto ao calor e faz a superfície do papel se romper. Conforme 
comenta a autora, a tecnologia precisa de impressora e papeis especiais, entretanto, é fácil de editar e reproduzir em escala, possibilitando a criação de linhas, formas e preenchimentos. Contudo, e é um sistema que apenas permite produzir mapas táteis monocromáticos (Gual et al., 2015). A Figura 3 mostra um exemplo da técnica.

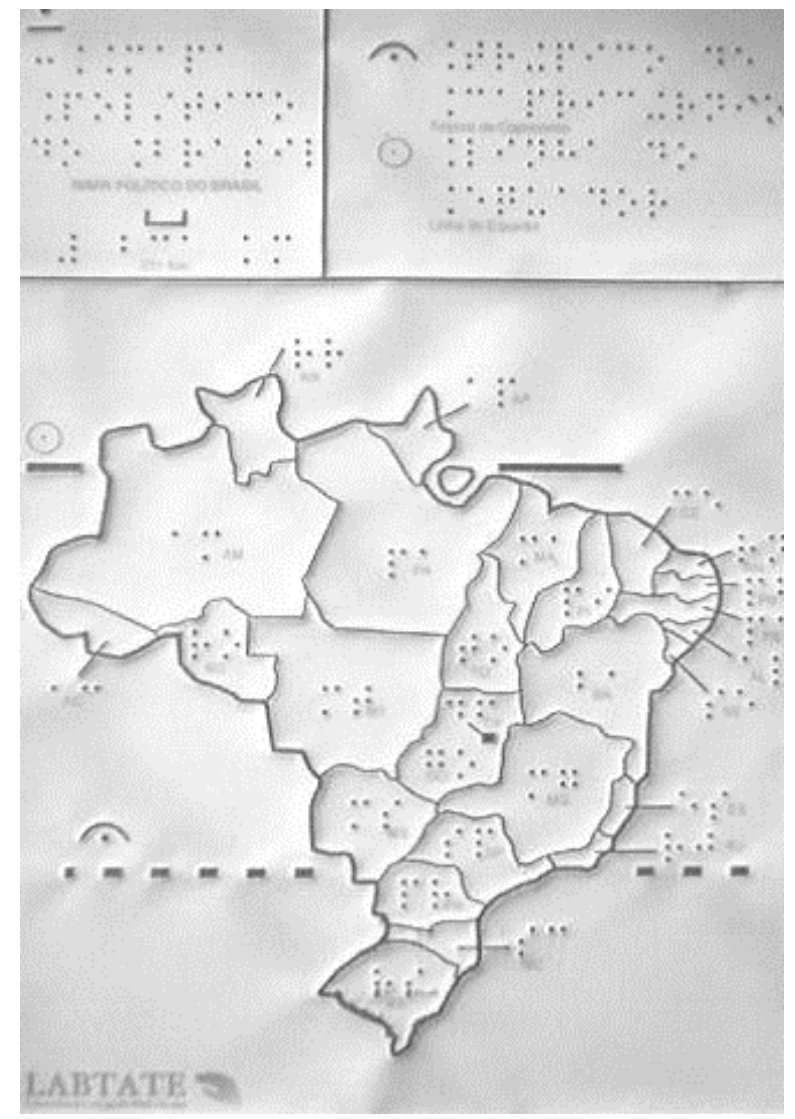

Figura 3. Divisão Política do Brasil em Relevo, impresso em papel microcapsulado. Fonte: Adaptado de LabTATE (2016).

A Termoformagem utiliza como base uma matriz construída artesanalmente ou com auxílio de computador, posteriormente coberta com plástico que passa por um processo de aquecimento e aspiração sobre a matriz original para reproduzir uma cópia desta. Possibilita variações em altura e textura e permite a produção em escala de cópias e adição de texto em Braille. É possível utilizar materiais plásticos com diferentes espessuras para criar produtos táteis com maior definição ou durabilidade (Araújo, 2018). 
A tecnologia de produção a partir da Prototipagem Rápida (Impressão em 3D) tende a produzir protótipos por meio de sistemas aditivos, ou seja, um processo de adição de material, camada por camada, permitindo a produção de protótipos ou modelos em três dimensões a partir de modelos geométricos gerados em sistemas CAD (Celani e Pupo, 2008).

As Figuras 4 e 5 apresentam respectivamente, um exemplo de uma maquete arquitetônica tátil e um mapa tátil dos biomas brasileiros, produzidos a partir da tecnologia da impressão em 3D. Uma das características que pode ser destacada desta tecnologia é a possibilidade de representação com grande resolução das texturas, símbolos e texto em braile facilitando a sua leitura, além da resistência do produto à dinâmica associada a sua leitura.

Atualmente muitas pesquisas têm sido realizadas utilizando o processo de fabricação a partir da tecnologia de impressão $3 \mathrm{D}$ para a produção de mapas e maquetes táteis, pois conforme afirmam Gual et al. (2015), a impressão 3D pode produzir geometrias complexas, o que permite combinar recursos visuais e táteis para gerar mapas dentro da perspectiva do Desenho Universal.

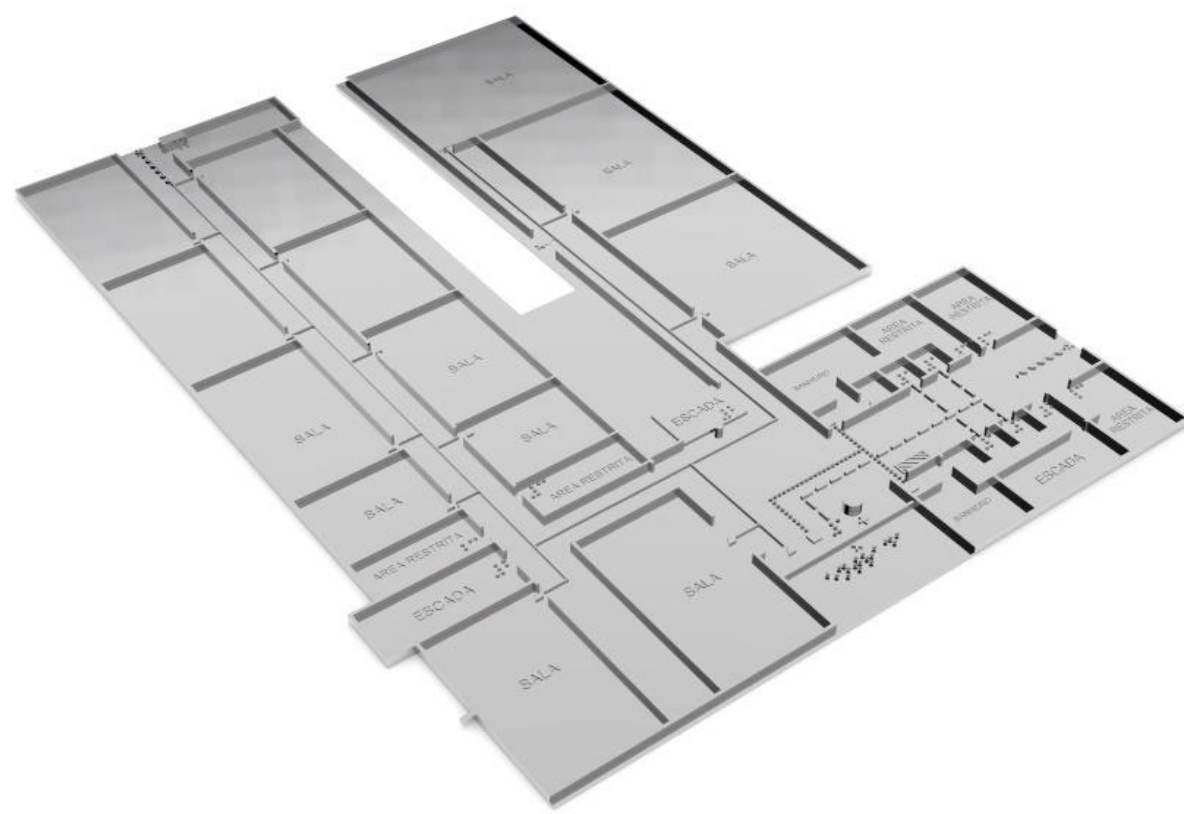

Figura 4. Pavimento térreo do prédio PA, localizado no Centro Politécnico da UPPR, em Curitiba - PR, impresso a partir da tecnologia da prototipagem rápida.

Fonte: Barrionuevo (2018). 


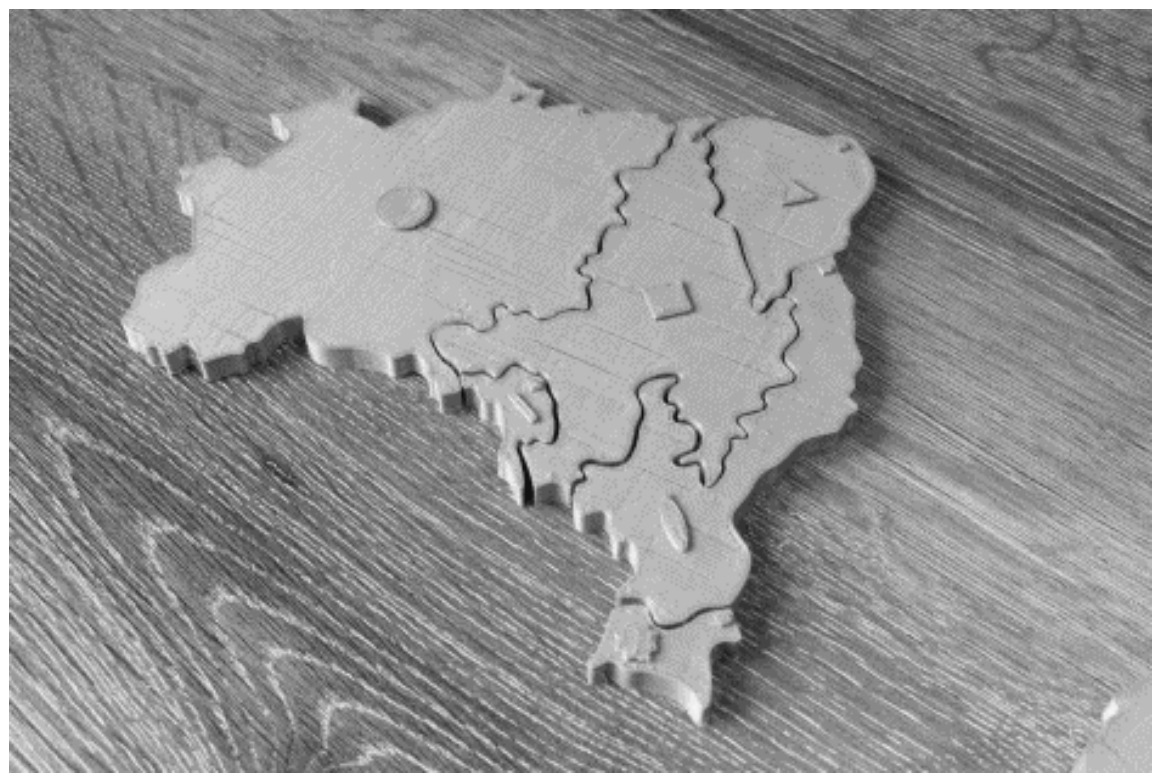

Figura 5. Mapa tátil dos biomas brasileiros para o ensino/aprendizagem de Geografia. Fonte: Andrade e Aguiar (2018).

\section{Simbologia Tátil}

Um mapa tátil, de acordo com Loch e Almeida (2006), deve ser um conjunto equilibrado de símbolos, texturas e elementos que passem a mensagem proposta com simplicidade, evitando o excesso de informações e, portanto, facilitando o entendimento do usuário. De acordo com o autor, as representações gráficas em textura e relevo que servem de orientação e localização para os usuários, também são usadas para a transmissão da informação espacial, portanto, essenciais para o ensino de História e Geografia, pois se reconhece que os mapas são a ligação para transmitir essas informações.

Milan (2008) cit. por Barriouevo (2018) comenta que, quando a pessoa com deficiência visual possui um contato direto com o ambiente, a formação da imagem do lugar e sua noção espacial são concebidas conforme sua experiência direta com o espaço. Porém, é ressaltado que este método é dependente do tempo para a formação desta imagem e isso nem sempre é possível. Isto é, o método é eficiente quando pessoa com deficiência visual possui uma frequência elevada neste mesmo ambiente, tendo tempo para memorizar qualquer objeto e/ou obstáculo nele inserido.

Segundo Barison (1999: 10), “a visão é, acima de tudo, um processo psicológico fortemente influenciado pelas experiências anteriores do indivíduo, ou seja, ninguém vê da mesma maneira, pois cada indivíduo tem a sua própria história”, ou seja, a 
percepção de uma imagem (ou de um símbolo) é determinada pela totalidade das experiências visuais pessoais com aquele objeto durante a vida (Fraccaroli, 1952). Portanto, a percepção da simbologia pictórica em um mapa depende da cultura do indivíduo, assim como da sua experiência visual.

De acordo com Almeida (2011) cit. por Araújo (2018), a semiologia gráfica proposta pelo francês Jacques Bertin na segunda metade do século XX utiliza propriedades de relações de semelhança, ordem e proporcionalidade entre os dados espaciais. Assim, todo símbolo gráfico possui um conceito vinculado ao seu significado que é expresso pela imagem por meio de variáveis visuais: tamanho, valor, textura, cor, orientação e forma. Estes princípios contribuíram para os fundamentos metodológicos da linguagem cartográfica, sua normatização e desenvolvimentos de símbolos convencionais.

Sobre a linguagem gráfica tátil, Almeida (2011) comenta que a maioria dos conceitos da semiologia gráfica e das suas aplicações práticas pode ser convertida por meio de variáveis acessíveis para pessoas com deficiência visual. Na cartografia tátil as variáveis gráficas visuais são adequadas para pessoas com deficiência visual, incluindo-se a variável volume nos símbolos, de modo que pessoas com deficiência visual ou com baixa visão possam interpretar as informações. Deste modo, a prioridade sensorial corresponde ao tato, considerando a facilidade de cognição. A Figura 6 representa um esquema de variáveis gráficas táteis.
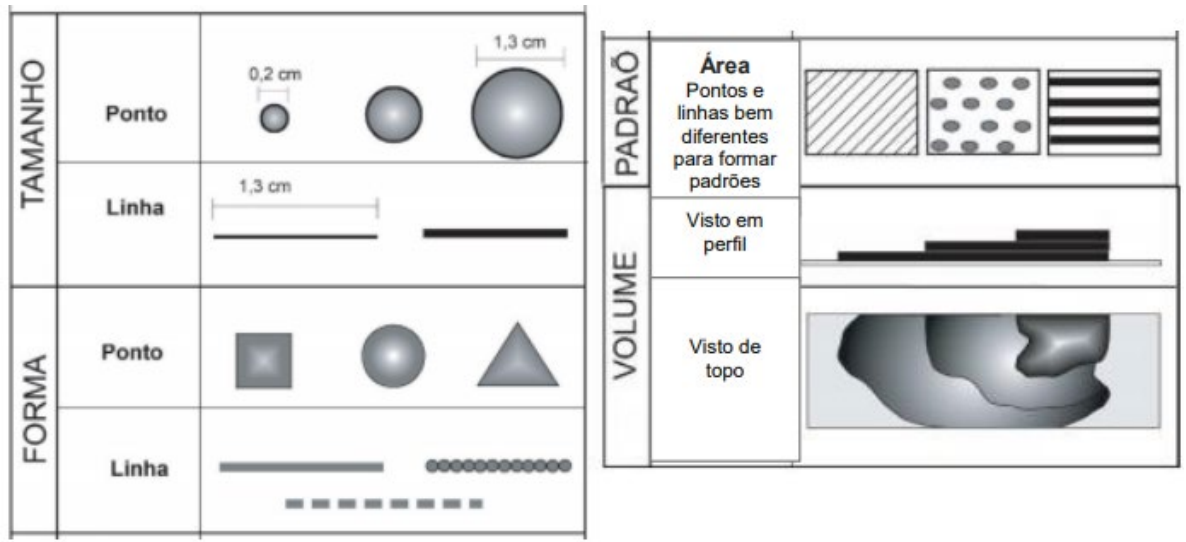

Figura 6. Variáveis gráficas táteis.

Fonte: Loch (2008).

Ainda não existe uma padronização para a produção de mapas táteis, relacionados tanto a simbologia, quanto aos materiais a serem utilizados para sua confecção. Entretanto, estudos que busquem uma padronização para pessoas com deficiência visual e com baixa visão se tornam importantes, assim como se busca no mapeamento 
de mapas para pessoas videntes, pois através da padronização, falhas na comunicação poderão ser evitadas.

Perdue e Lobben (2016) concluíram em sua pesquisa que existe uma relação entre a experiência em 'leitura' de mapas táteis com o desempenho em relação ao seu uso, o que indica um aumento na utilização de mapas táteis como ferramenta de ensino às crianças com deficiência visual, pois desta forma, a experiência e o contato com a simbologia facilitará as tarefas referentes ao seu uso. Além disso, os autores recomendam que mais pesquisas sejam realizadas a fim de avaliar padrões perceptivos e cognitivos das pessoas com deficiência visual e com baixa visão.

Na pesquisa de Araújo (2018), buscou-se avaliar a cognição tátil de símbolos cartográficos semânticos da área de estudo que possam ser reproduzidos por meio de impressora 3D, como intuito de uma demanda de convenções cartográficas normativas para desenvolvimento de símbolos para mapa tátil de ambiente indoor. Os símbolos usados foram concebidos a partir de uma relação semântica aos conceitos a que os símbolos representavam, como exemplos, a sala de professores remete à ideia de uma caricatura simplificada de coruja (símbolo da sabedoria) com seus olhos e bico; a secretaria foi representada por um clipe (Figura 7a e 7b).

A partir dos resultados obtidos pela autora, pôde-se evidenciar que a proposta de elaborar símbolos intuitivos para pessoas com deficiência visual é algo desafiador na cartografia tátil, pois a forma e o significado filosófico dos símbolos precisam ser previamente conhecidos pelo usuário para o estabelecimento da associação entre o desenho do símbolo e o seu significado. Sem este treinamento prévio, segundo Araújo (2018), o usuário provavelmente terá uma postura indiferente relacionada à intuitividade do símbolo.

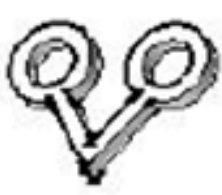

(a)

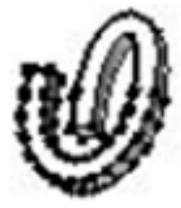

(b)

Figura 7. Símbolos táteis utilizados para representar: a sala de professores (coruja simplificada), em a; e a secretaria, representada por um clipe, em b. Fonte: Adaptado de Araújo (2018).

Desta forma, este estudo teve como objetivos além de contribuir com pesquisas voltadas a discussões sobre símbolos táteis, avaliar a possibilidade de utilização de símbolos pictóricos na produção de mapas táteis voltados ao Desenho Universal de Aprendizagem (DUA). Nessa pesquisa, o termo pictórico refere-se aos símbolos que 
reproduzem alguma característica visual do objeto que representam, e assim podem ser relacionados com a imagem ou ao conceito do objeto representado (Robinson et al., 1984; Forrest e Castner, 1998). Este tipo de símbolo é utilizado de forma eficaz no mapeamento temático para pessoas videntes, já que os mesmos necessitam de menos consultas à legenda, pois o próprio símbolo conduz a um interpretante, que representa seu objeto.

Portanto, como hipótese, esperou-se que os símbolos pictóricos táteis concebidos de forma muito próxima ao objeto referente, facilitassem a percepção e o aprendizado dos conteúdos de Geografia apresentados nos mapas, por todas as crianças, sendo deficientes visuais ou não. Preconizando, assim, os princípios básicos do DUA e as afirmações de Vigotski (1989), ou seja, orientando o aprendizado no sentido de proporcionar a integração e à socialização das crianças com deficiência visual no ambiente escolar, utilizando-se da percepção visual de outra pessoa (a experiência alheia) como instrumento para ver, e principalmente a linguagem.

Além disso, considerou-se a viabilidade de pessoas com deficiência visual memorizarem e reconhecerem símbolos cartográficos pictóricos, assim, a cartografia tátil poderá avançar na criação de normas para elaboração de símbolos com tecnologia de impressão 3D.

\section{Mapas Concebidos para avaliar a Compreensão dos Símbolos Táteis}

Para esse estudo decidiu-se utilizar um mapa do Brasil com as principais informações do Setor Agropecuário (Figura 8). O uso atualizado das informações dos dados presentes nos mapas não foi considerada relevante, já que o objetivo da pesquisa foi o de avaliar a compreensão da simbologia pictórica tátil. Além disso, procurou-se um mapa com poucas informações, para facilitar os testes com os usuários.

A partir dos símbolos disponíveis no mapa utilizado, foram testados cinco símbolos que representam o Setor Agropecuário: soja; café; cana de açúcar; milho e carne bovina.

Foram concebidos dois mapas para o estudo:

- Mapa 1. símbolos pictóricos (Figura 8) representando cada produção do estado: a produção de bovinos do estado do Mato Grosso do Sul representado pelo animal 'boi';

- Mapa 2. o segundo mapa foi construído com os símbolos abstratos, os quais já são utilizados na Cartografia Tátil (Figura 9).

Os mapas foram confeccionados a partir da modelagem 3D no software Rhinoceros e impressos gratuitamente através da tecnologia da Prototipagem Rápida (impressão 3D) no FabLab, um espaço de colaboração entre estudantes comunidades e empresas. A impressora utilizada foi a Cliever 52 CL2 Pro e o filamento foi o PLA (ácido polilático). O PLA, apesar de ser um material considerado menos flexível, tem capacidade de produzir peças mais precisas e com um preço mais acessível. 


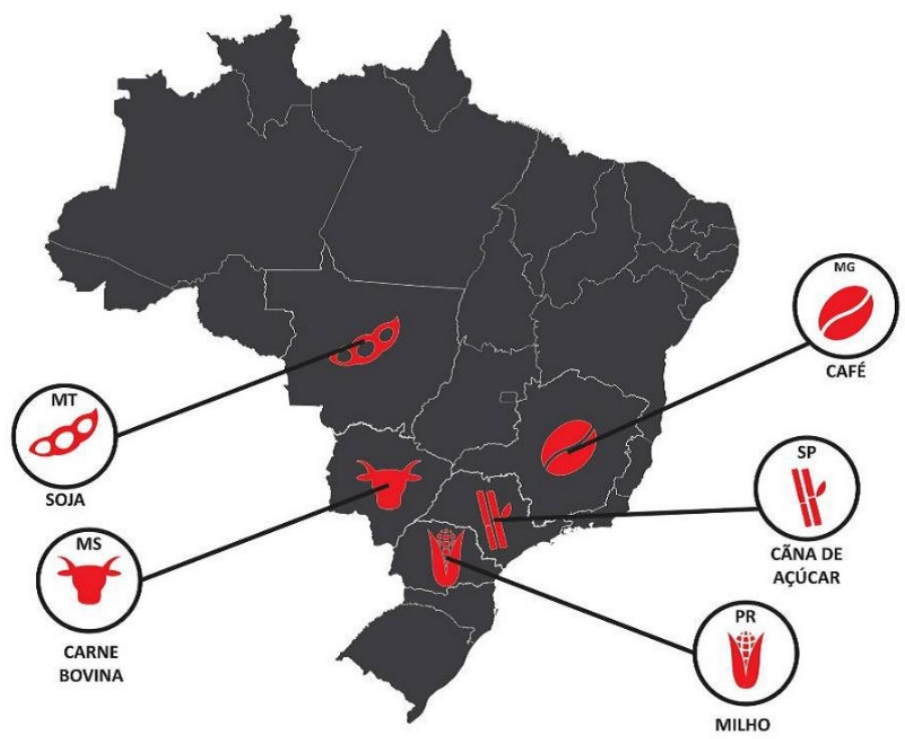

Figura 8. Mapa com a Simbologia Pictórica, utilizado para os testes de percepção tátil. Fonte: As autoras.

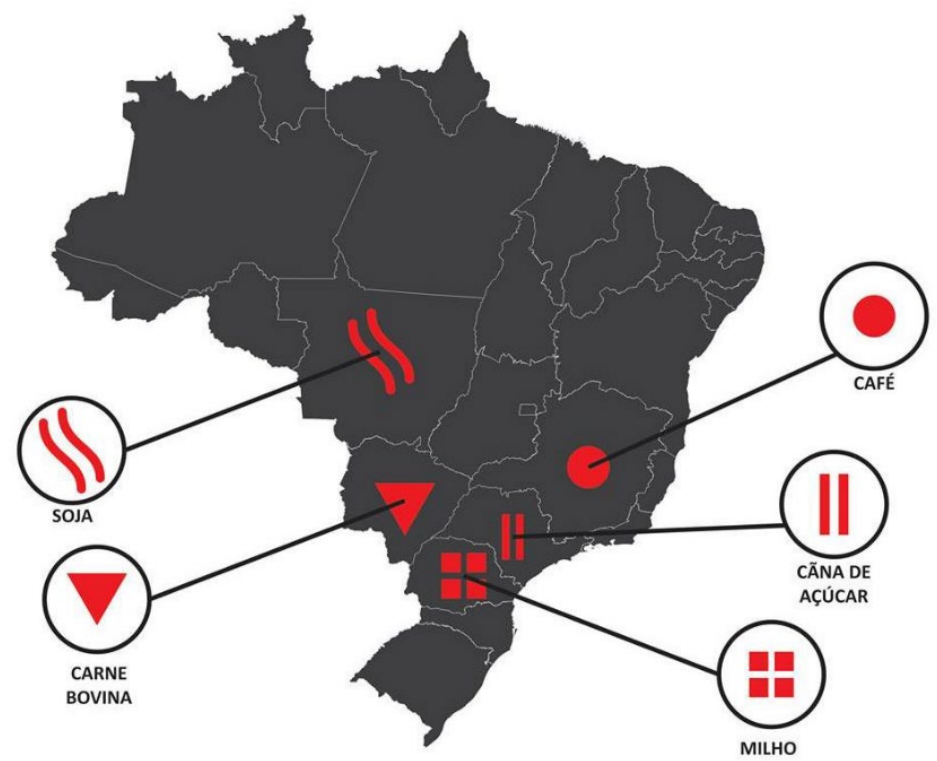

Figura 9. Mapa com a Simbologia Abstrata, utilizado para os testes de percepção tátil. Fonte: As autoras. 
O layout do mapa foi produzido, baseando-se nos resultados obtidos por Loch (2008), que desenvolveu um padrão no qual os elementos táteis ficam em locais prédefinidos (Figura 10), sendo o título e as informações da legenda apresentados na parte superior do mapa. A autora comenta que, essa disposição dos elementos segue a forma mais ergonômica de leitura - a leitura de um texto se faz da esquerda para a direita e de cima para baixo, também na escrita em braile. Além disso, facilita a exploração tátil, pois a pessoa com deficiência visual primeiramente explora o todo, ou seja, os contornos da área mapeada; depois, com auxílio da legenda, vai interpretando as partes: os elementos pontuais, os limites internos que constituem áreas e os elementos lineares, caso existam.

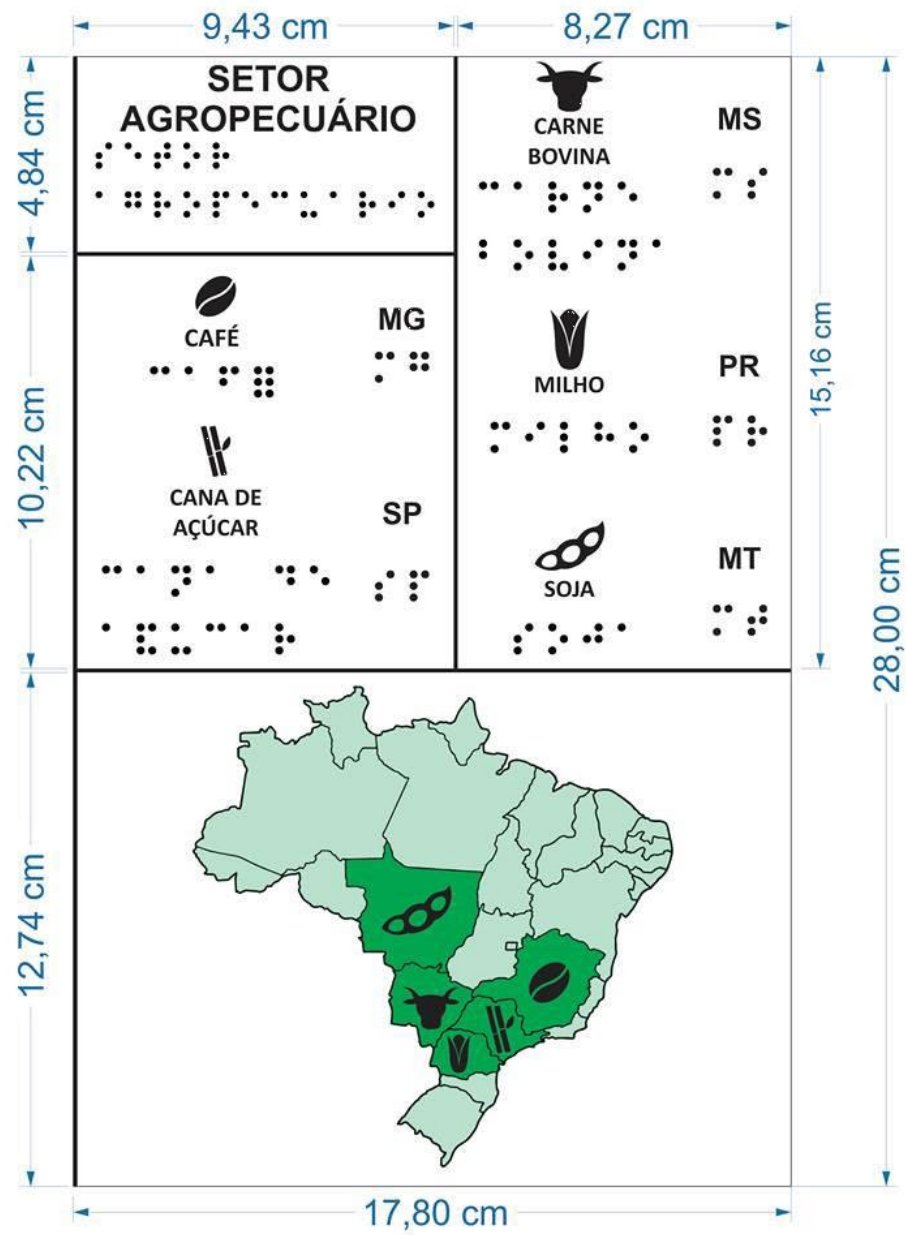

Figura 10. Layout do mapa com a simbologia pictórica, usado na pesquisa. Fonte: As autoras. 
A Figura 11 mostra o mapa impresso a partir da tecnologia de impressão 3D. A mesma foi realizada com o material disponível no FabLab, entretanto, a cor branca não foi considerado ideal, pois dificultou a percepção dos símbolos para os alunos videntes. A base foi produzida com $4 \mathrm{~mm}$ de espessura, as informações de texto (para os videntes) foram apresentadas em baixo-relevo com $1 \mathrm{~mm}$, e o Braile, assim como os símbolos temáticos, foram confeccionados com $1 \mathrm{~mm}$ de altura.

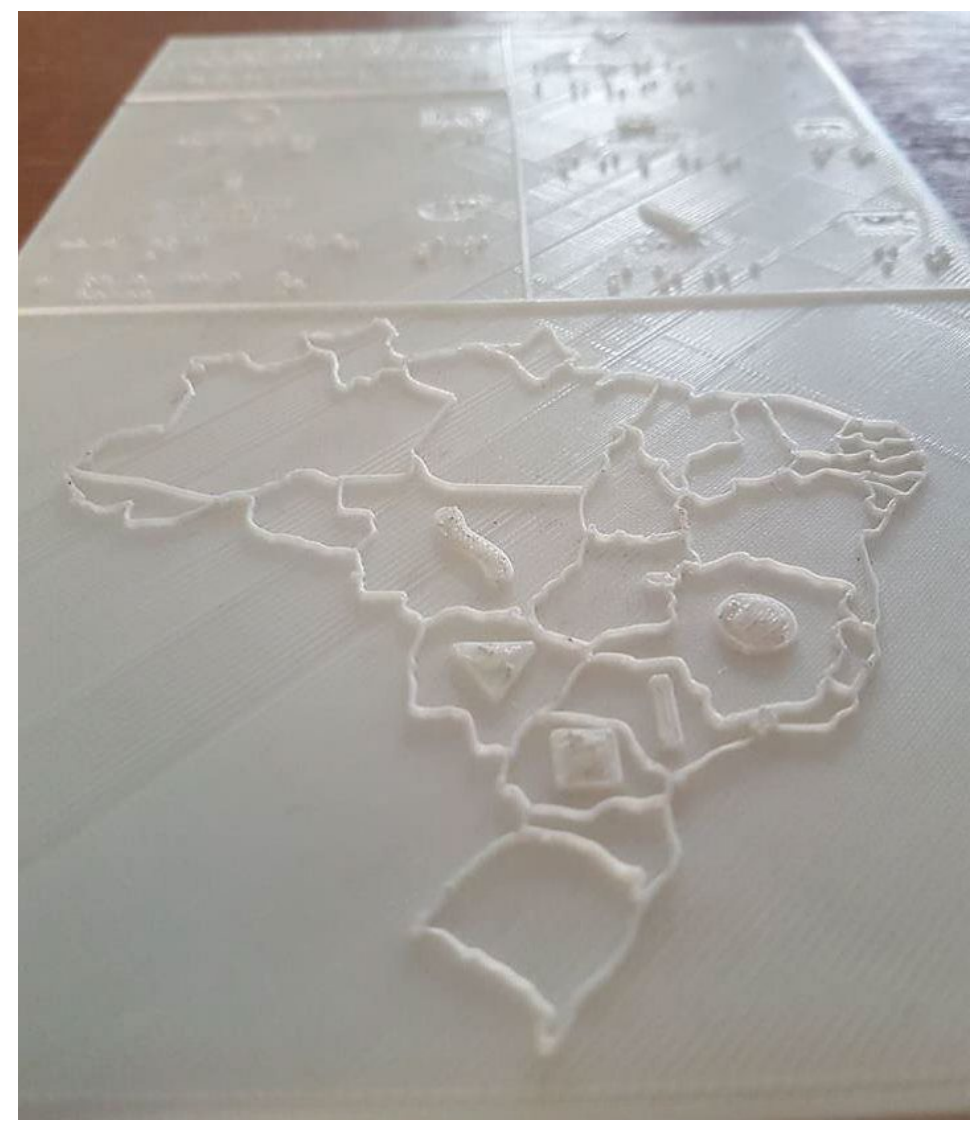

Figura 11. Detalhe do mapa tátil impresso em 3D.

Fonte: As autoras.

Os símbolos táteis foram concebidos com um tamanho suficiente para que os diferentes visuais o sentissem por inteiro abaixo da ponta do dedo (Figura 12), conforme preconiza Jehoel (2007). De acordo com os resultados obtidos em sua pesquisa, Jehoel (2007) comenta que os símbolos maiores são mais fáceis de usar e de sentir, entretanto, quando são exagerados podem dificultar o entendimento. 

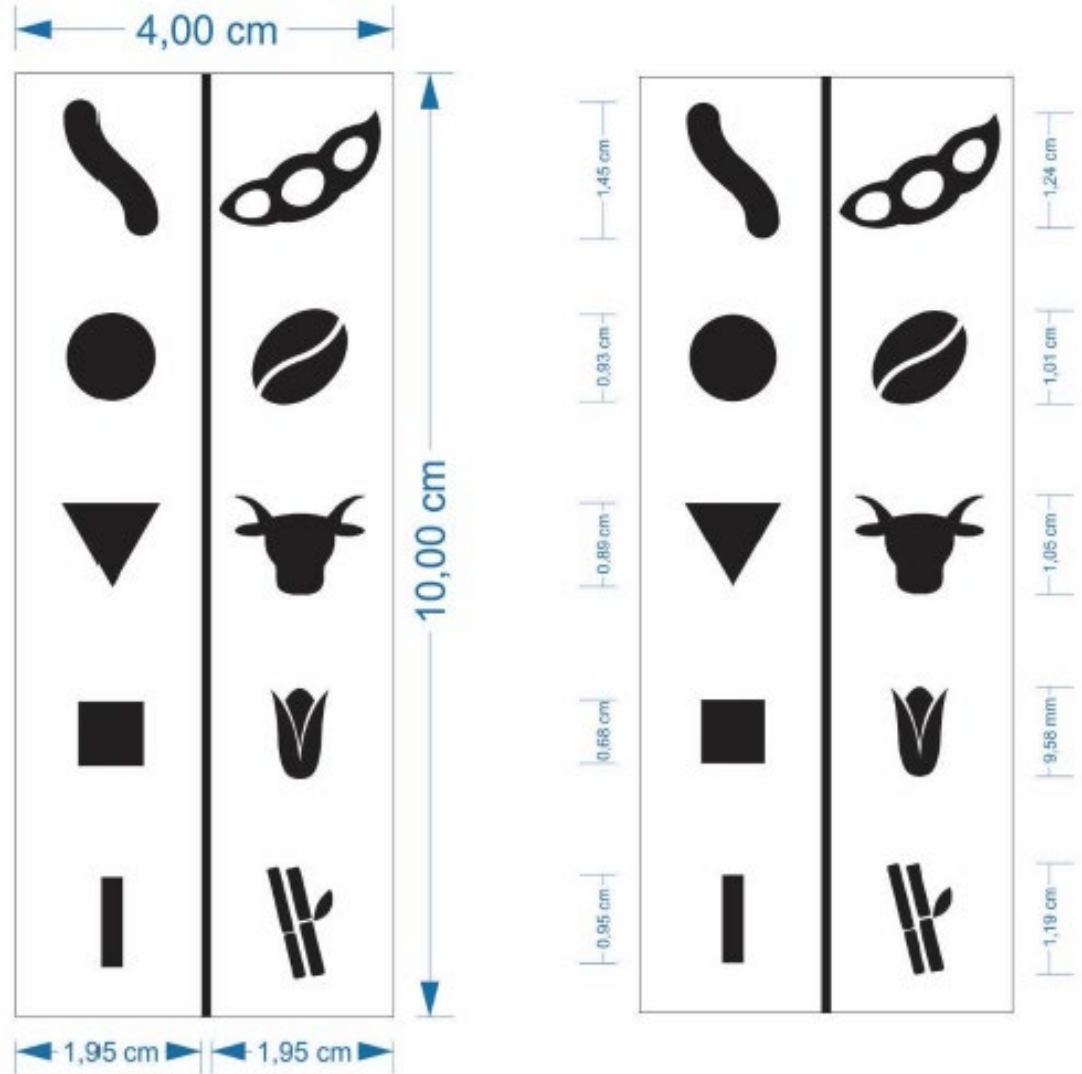

Figura 12. Representação gráfica dos símbolos abstratos x pictóricos utilizados na Tarefa 1 . Fonte: As autoras.

\section{Avaliação da Compreensão dos Símbolos Táteis}

Os testes de percepção foram realizados com três estudantes de 15 anos de idade, com deficiência visual; e dois videntes de 12 anos, do ensino fundamental de $7^{\circ}$ e $8^{\circ}$ séries respectivamente, do Colégio Dom Pedro II, em Curitiba/PR. Como é um colégio voltado à educação inclusiva, o número de participantes se restringiu a disponibilidade dos alunos presentes nos dias agendados para a avaliação, além da instituição não possuir um número expressivo de estudantes com deficiência visual. Desta forma, o presente estudo se enquadra no tipo de pesquisa qualitativa exploratória, ou seja, que se dedica a determinado tema pouco explorado e de difícil elaboração de hipóteses precisas (Gil, 2017). De acordo com Gil (2017), este tipo de pesquisa proporciona maior familiaridade com o problema, tornando-o mais explícito. 
Nesse trabalho, todos os alunos com deficiência possuíam a deficiência visual congênita, ou seja, nasceram sem o sentido da visão, e desta forma, não possuem uma informação visual do mundo, diferentemente das pessoas que possuem deficiência visual adquirida. Todos os estudantes possuíam níveis cognitivos em conformidade a idade. As tarefas de percepção foram realizadas em ambiente de sala de aula, com a supervisão da professora especialista em educação inclusiva. A professora não interferiu nas tarefas de percepção, apenas após a realização das mesmas a docente e os alunos puderam interagir com o material, pois os estudantes se motivaram a explorar mais o mapa, e houve uma 'discussão' sobre os temas representados.

Para os testes de percepção, os símbolos foram avaliados em duas fases:

- Tarefa 1. Percebendo os símbolos isoladamente, fora do contexto do mapa, tendo os símbolos abstratos e os pictóricos lado a lado (Figura 13). Nesta tarefa o estudante deveria indicar de forma oral a opção mais adequada à representação de cada cultura, além de responder o motivo pelo qual fez a escolha. Esta tarefa foi realizada por todos os alunos.

O objetivo desta tarefa foi investigar os parâmetros de tamanho de impressão dos símbolos, assim como a compreensão e preferência da simbologia.

- Tarefa 2. A partir da leitura tátil no contexto do mapa. Nesta etapa, o teste foi realizado com os símbolos no contexto do mapa, utilizando-se das informações da legenda.
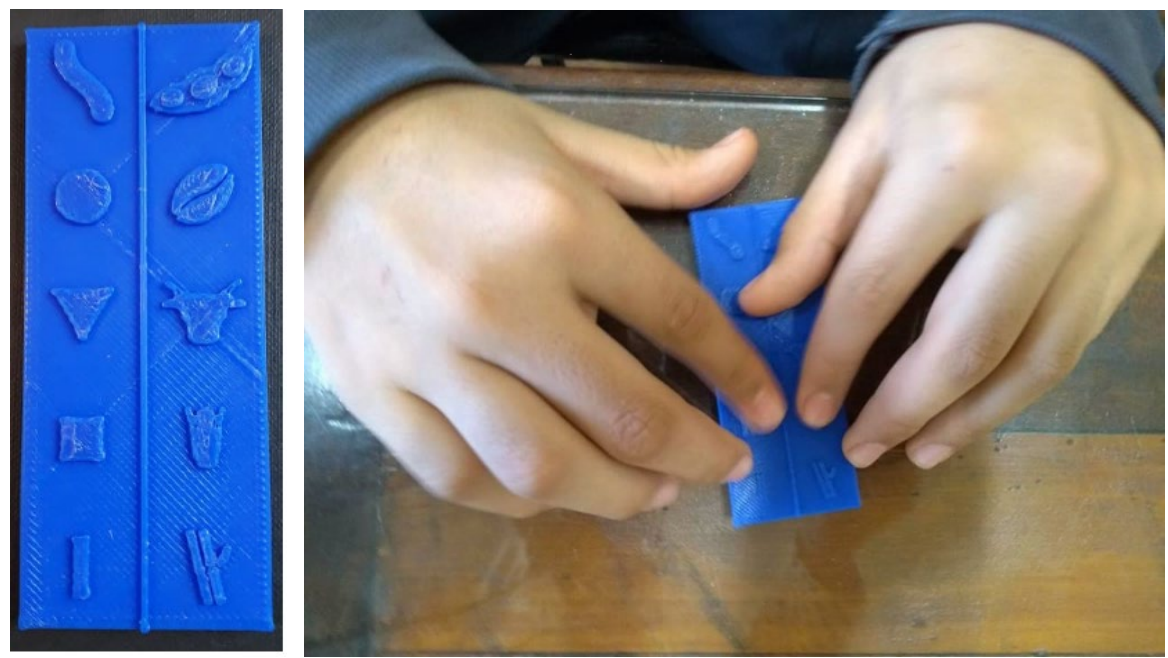

Figura 13. Placa com os símbolos abstratos x pictóricos, impressa em 3D e utilizados na Tarefa 1.

Fonte: As autoras. 
Nesta tarefa, se buscou aferir qual das simbologias facilita a compreensão da informação apresentada no mapa. Além disso, buscou-se avaliar a composição dos elementos do mapa, utilizada por Loch (2008). A tarefa foi realizada em duas fases, na primeira os alunos responderam às seguintes questões, sem consulta a legenda:

- ¿Qual é o país está representado neste mapa?

- ¿Consegue perceber símbolos em alguns estados?

- ¿Você sabe quais são estes estados?

$\mathrm{O}$ objetivo desta primeira fase foi investigar a experiência dos estudantes em relação ao uso de mapas, já que conforme informações fornecidas pela professora especialista, há uma carência na disponibilidade de materiais táteis para os conteúdos de Geografia.

$\mathrm{Na}$ segunda parte, os alunos responderam às seguintes questões, consultando a legenda:

- ¿Qual o título do mapa?

- ¿Qual o estado produtor de carne bovina?

O objetivo desta segunda fase foi investigar os parâmetros de tamanho da impressão do Braile, o posicionamento da legenda, assim como à compreensão e preferência da simbologia no contexto do mapa.

\section{Resultados e discussões}

O objetivo da primeira tarefa foi investigar os parâmetros de tamanho de impressão dos símbolos, assim como a compreensão e preferência da simbologia. Os resultados podem ser observados a partir do Quadro 1. Observando os resultados, nota-se que todos os participantes escolheram o símbolo pictórico para a melhor representação do 'milho', assim como dois dos três participantes escolheram o símbolo de soja para representar o tema na forma pictórica. Para os demais símbolos, dois dos três participantes disseram preferir os símbolos abstratos como a melhor forma de representação.

Nessa tarefa os alunos tiveram bastante curiosidade sobre os símbolos representados, o que demonstrou interesse e curiosidade na forma de representação pictórica. Após a aplicação dos testes, devido à curiosidade das crianças pelos 'desenhos' representados na forma pictórica, houve uma discussão sobre os temas representados no mapa. Dois dos alunos, Carlos e Maria, tiveram dificuldade de entender o que era cana de açúcar e houve uma breve explicação sobre do que se tratava a cultura.

A professora utilizou da comparação da bengala utilizada por eles para se locomover, para explicar o formato da cultura. $\mathrm{O}$ aluno Mateus teve dificuldades de 


\section{Quadro 1}

Resultados da Tarefa 1 - Preferência dos participantes entre os símbolos

Pictórico x Abstrato

\begin{tabular}{|c|c|c|}
\hline Descrição & $\begin{array}{l}\text { Símbolo } \\
\text { Pictórico }\end{array}$ & $\begin{array}{l}\text { Símbolo } \\
\text { Abstrato }\end{array}$ \\
\hline Soja & 2 & 1 \\
\hline Café & 1 & 2 \\
\hline Milho & 3 & 0 \\
\hline Cana de açúcar & 1 & 2 \\
\hline Carne Bovina & 1 & 2 \\
\hline
\end{tabular}

Fonte: As autoras.

identificar as diferenças dos símbolos abstratos para os pictóricos e precisou de uma nova explicação sobre o teste, pois estava notando apenas a diferença de tamanho, porém, posteriormente conseguiu identificar detalhes nos símbolos que os outros alunos não perceberam, como os chifres do boi que representavam a carne bovina, ele também foi o único aluno que possuía o conhecimento da cana de açúcar.

O que se pôde observar foi que a percepção da simbologia pictórica por parte dos deficientes visuais tornou-se mais atrativa, isto pôde ser percebido pela empolgação quando os mesmos sabiam que as formas expostas representavam o desenho da cultura agrícola 'na realidade'. Entretanto, assim como ocorre com as pessoas videntes, a percepção depende da memória visual, ou seja, para a compreensão e identificação de um símbolo pictórico, a imagem mental é determinada pela totalidade das experiências visuais pessoais com aquele objeto durante a vida (Fraccaroli, 1952). Isso pôde ser observado com o símbolo de 'milho', que já é um alimento mais presente no dia a dia das pessoas.

Estas observações parecem confirmar as abordadas por Vygotski (1997), de que os mapas com a simbologia pictórica podem estimular os alunos com deficiência visual à interação social e a utilizar além do tato, a linguagem, o que contenta os princípios do Desenho Universal. 
A segunda tarefa, como comentado, teve como objetivo avaliar a composição dos elementos do mapa, assim como testar os símbolos no contexto do mapa. Dos três participantes, apenas o aluno Mateus conseguiu identificar e ainda conseguiu associar o mapa com os símbolos apresentados na placa da tarefa anterior. Os demais participantes não conseguiram identificar a forma do contorno do país, e a partir de alguns questionamentos, confessaram não terem experiência com a manipulação de mapas táteis, comprovando o que foi comentado pela educadora, de que há uma escassez de materiais didáticos, e principalmente para o ensino de Geografia. Além disso, novamente comprova a importância da experiência/memória 'visual' na percepção dos elementos presentes no mapa.

Nas tarefas com a utilização da legenda, todos os participantes, conseguiram responder sem dificuldade a resposta utilizando a legenda e a simbologia para ambos os mapas testados. Os alunos também conseguiram compreender as informações em Braile, conseguiram identificar todos os estados e suas respectivas culturas. Desta forma, os parâmetros de espessura utilizados na impressão foram considerados eficazes pelos participantes.

Os dois alunos videntes que participaram da pesquisa não tiveram dificuldades quanto à compreensão de ambas as simbologias, contudo, elegeram a pictórica como a mais atrativa e a mais fácil de compreender.

\section{Considerações finais}

O objetivo geral dessa pesquisa foi verificar a possibilidade da utilização de símbolos pictóricos táteis nas representações de mapas temáticos para que os mesmos possam ser percebidos e compreendidos, tanto para pessoas com deficiência visual quanto para os videntes, nos usos destes mapas.

A partir das tarefas realizadas com os participantes, sugere-se que a simbologia pictórica seja indicada a ser utilizada para a representação de feições pontuais no mapeamento tátil, pois além de ser mais agradável, torna-se mais fácil por não necessitar da constante consulta a legenda, bem como promove a socialização e à inclusão dos alunos com deficiência visual. Entretanto, assim como ocorre com os videntes, a compreensão do símbolo depende das experiências visuais pessoais com aquele objeto durante a vida, conforme preconiza Fraccaroli (1952), além da cultura do indivíduo.

Assim como ocorre com a utilização de símbolos pictóricos para pessoas videntes, alguns símbolos são apreendidos na medida em que os mesmos são observados e utilizados no dia a dia, o que os tornam passíveis a uma padronização, sendo empregados de forma universal. Desta forma, percebe-se que os símbolos pictóricos são passíveis de serem utilizados, entretanto, sugere-se que testes com mais pessoas sejam realizados a fim de comprovar os resultados obtidos, inclusive para aferir o nível de detalhe de cada um dos símbolos. Além disso, sugere-se que sejam aplicados 
com estudantes videntes, com baixa visão e com deficiência visual adquirida, a fim de validar a utilização dentro dos princípios da DUA.

A partir dos resultados, pôde-se também concluir que os mapas táteis com a simbologia pictórica são ferramentas úteis na inclusão para o ensino dos conteúdos de Geografia, pois despertou interesse tanto para os alunos com deficiência visual quanto para os videntes, e os mesmos puderam utilizar o mesmo material. Além disso, esta interação com os demais estudantes permite a complementação de conhecimentos que vão além do que está representado no mapa.

Existem inúmeros processos que podem ser produzidos os mapas táteis, porém, notou-se a partir desse estudo, uma carência em materiais inclusivos para esses alunos na sala de aula regular. A Impressão 3D se mostrou uma ferramenta útil para a fabricação de materiais táteis devido a sua durabilidade, além de poder ser replicado com facilidade. Além disso, a impressão com o material PLA utilizado, apesar de proporcionar uma textura, devido ao material e precisão de acabamento de impressão, não influenciou na identificação dos símbolos e nas demais informações presentes no mapa. As dimensões utilizadas nas informações textuais, assim como para os símbolos também foram consideradas satisfatórias.

\section{Bibliografía}

Almeida, R.A. (2011). "A cartografia tátil na USP: duas décadas de pesquisa e ensino", in Cartografia tátil: orientação e mobilidade às pessoas com deficiência visual, Maria Isabel C. de Freitas e Silvia Helena Ventorini (org.), São Paulo, Jundaí, Paco Editorial, 2011, pp. 138-167.

Alves, M.M., Ribeiro, R., Simões, F. (2013). "Universal design for learning (UDL): Contributos para uma escola para todos", Tecnologias da Informação em Educação, Indagatio Didactica, 5(4), pp. 121-146.

Andrade, A.F.; Aguiar, B.C.X.C. (2018). "O Uso de Mapas Táteis no Auxílio do Processo de Ensino-Aprendizagem por meio do Desenho Universal". VII Congreso Internacional y XV Congreso Nacional de Profesores de Expresión Gráfica en Ingeniería, Arquitectura y Carreras Afines: campos, umbrales y poéticas del dibujo", Egrafia Argentina, La Plata, Buenos Aires, Argentina, Anais, 4 a 6 de octubre de 2018.

Araújo, N.S. (2018). "Desenvolvimento de Símbolos para Mapa Tátil Indoor a parti de Impressora 3D", dissertação de Mestrado, Curso de Pós-Graduação em Engenharia Civil, Universidade Federal da Bahia, 146 pp.

Barison, M.B. (1999). "Desenvolvimento da Percepção Espacial e Expressão Gráfica", Semina: Ci. Soc./Hum., vols. 19-20, no. 3, set., Londrina, 1999, pp. 9-22.

Barrionuevo, J. (2018). "O Uso da Fabricação Digital na Confecção de Maquete Tátil para Pessoas com Deficiência Visual”, Monografia de Conclusão de Curso, Curso 
de graduação em Bacharelado em Expressão Gráfica, Universidade Federal do Paraná, 79 pp.

Carletto, A.C.; Cambiaghi, S. (2018). "Desenho Universal: um conceito para todos". Recuperado de $<$ http://maragabrilli.com.br/>, acesso em 05 de junho de 2018.

Celani, G.; Pupo, R. (2008). "Prototipagem rápida e fabricação digital para arquitetura e construção: definições e estado da arte no Brasil", Cadernos de Pós-Graduação em Arquitetura e Urbanismo, São Paulo, Universidade de Campinas, 2008.

Center for Applied Special Technology —CAST (2011). Universal Design for learning guidelines version 2.0. Wakefield, MA: Author.

Dean, T.; Lee-Post, A; Hapke, H. (2017). "Universal Design for Learning in Teaching Large Lecture Classes", Journal of Marketing Education, vol. 39, no. 1, pp. 5-16.

Edyburn, D.L. (2010). "Would you recognize Universal Design for Learning if you saw it? ten propositions for new directions for the second decade of Udl", Learning Disability Quarterly, vol. 33, no. 1, pp. 33-41.

Forrest, D.; Castner, H.W. (1998). "On the design of point symbols for tourist maps: enclosed or not enclosed is not the question!", The Cartographic Journal, vol. 35, pp. 79-81.

Fraccaroli, C.A. (1952). “A percepção da forma e sua relação com o fenômeno artístico - o problema visto através da Gestalt (psicologia da forma)", São Paulo, FAUUSP, 1982, $1^{\mathrm{a}} \mathrm{Ed}$.

Gil, A.C. (2017). "Como elaborar projetos de pesquisa", 6 eds., São Paulo, Atlas.

Gual, J., Puyuelo, M. and Lloveras, J. (2015). "Improving Tactile Map Usability through 3D Printing Techniques: An Experiment with New Tactile Symbols", The Cartographic Journal, vol. 52, no. 1, pp. 51-57.

Jehoel, S. (2007). "A series of psychological studies on the design of tactile maps". These, University of Surrey, Guilford.

Katz, J. (2013). "The three block model of Universal Design for Learning (UDL): engaging students in inclusive education", Canadian Journal of Education, vol. 36, no. 1, pp. 153-194.

Kolacny, A. (1977). “Cartographic Information - A Fundamental Concept and Term in Modern Cartography”, Cartographica, Suplemento no. 1, vol. 14, pp. 39-45.

Lira, M.C.F.; Schlindwein, L.M. (2008). "A pessoa cega e a inclusão: um olhar a partir da psicologia histórico-cultural”, Cad. Cedes, vol. 28, no. 75, Campinas, pp. 171-190.

Loch, R.E.N. (2008). “Cartografia tátil: mapas para deficiente visuais”, Portal da cartografia, vol. 1, no. 1, 2008, Londrina - PR. Recuperado de $<$ http://wwww.uel.br/revistas/uuel/index.php/portalcartografia $>$. 
Loch, R.E.N.; Almeida, de L.C. (2006). "Uma cartografia muito especial a serviço da inclusão social", in Congresso Brasileiro de Cartografia, 2, Florianópolis. Anais... Florianópolis. [s.n.].

Lopéz, J.L. (2012). "Facilitadores de la inclusión”, Revista Educación Inclusiva, vol. 5, núm. 1, pp. 175-187.

Milan, L.F. (2008). "Maquetes táteis: infográficos tridimensionais para a orientação espacial de deficientes visuais", PARC Pesquisa em Arquitetura e Construção, Campinas, SP, vol. 1, no. 2, jun., pp. 99-124.

Nogueira, R.E. (2010). "Mapas como facilitadores na inclusão social de pessoas com deficiência visual", ComCiência. no. 123.

Nunes, C., Madureira, I. (2015) "Desenho Universal para a Aprendizagem: Construindo práticas pedagógicas inclusivas", Da Investigação às Práticas, vol. 5, no. 2, pp. 126-143.

Oka, M.W.; Raoa, K.; Bryantb, B.R.; McDougalla, D. (2017). Universal Design for Learning in Pre-K to Grade 12 Classrooms: A Systematic Review of Research. Exceptionality, 2017, vol. 25, no. 2, pp. 116-138.

Perduen, N.A.; Lobben, A.K. (2016). "Understanding Spatial Pattern Cognition from Tactile Maps and Graphics", The International Journal for Geographic Information and Geovisualization, vol. 51, no. 2, pp. 103-110.

Robinson, A.H., Sale, R.D., Morrison, J.L. and Muehrcke, P.C. (1984). "Elements of cartography", 5th ed., New York, John Wiley.

Sluter, C.R. (2008). "Uma Abordagem Sistêmica para o Desenvolvimento de Projeto Cartográfico como Parte do Processo de Comunicação Cartográfica", Portal da Cartografia, Londrina, vol.1, no.1, pp. 1-20.

Vygotski, L.S. (1989). "Obras escogidas. Tomo V. Fundamentos de defectología”, Cuba, Editorial Pueblo y Educación.

—. (1997), Obras escogidas: V. Fundamentos de defectología, Madrid, Visor. 